Research Article

\title{
Sutureless Intrascleral Posterior Chamber Intraocular Lens Fixation: Analysis of Clinical Outcomes and Postoperative Complications
}

\author{
Jiannan Liu, ${ }^{1}$ Wenxue Fan, ${ }^{2}$ Xinyu Lu, ${ }^{2}$ and Shaomin Peng $\mathbb{D}^{1,2}$ \\ ${ }^{1}$ Aier School of Ophthalmology, Central South University, Changsha, China \\ ${ }^{2}$ Harbin Aier Eye Hospital, Harbin, China \\ Correspondence should be addressed to Shaomin Peng; psmeye@163.com
}

Received 1 September 2020; Revised 22 December 2020; Accepted 6 January 2021; Published 16 January 2021

Academic Editor: Paolo Mora

Copyright (c) 2021 Jiannan Liu et al. This is an open access article distributed under the Creative Commons Attribution License, which permits unrestricted use, distribution, and reproduction in any medium, provided the original work is properly cited.

Purpose. To report a technique for performing sutureless intrascleral fixation of a posterior chamber intraocular lens (PC-IOL) and analyzing the clinical outcomes and postoperative complications. Study Design. 68 eyes of 66 patients who received the technique were studied retrospectively. Methods. The best-corrected visual acuity (BCVA), intraocular pressure (IOP), anterior chamber depth (ACD), IOL tilt and decentration, corneal topography (K1 and $K 2$ ), and postoperative complications were determined at 3 months. Results. The mean preoperative BCVA was $1.63 \pm 1.24 \log M A R$ units, and the mean postoperative BCVA was $0.74 \pm 0.59 \log$ MAR units at 3 months $(P<0.05)$. The mean preoperative IOP was $21.9 \pm 12.6 \mathrm{mmHg}$, and the mean postoperative IOP was $16.9 \pm 4.5 \mathrm{mmHg}$ at 3 months $(P=0.001)$. The mean preoperative corneal topography (K1 and $\mathrm{K} 2)$ was $K 1=42.14 \pm 1.91$ and $K 2=43.54 \pm 1.51$; the mean postoperative corneal topography $(K 1$ and $K 2)$ was $K 1=43.03 \pm 2.18$ and $K 2=43.40 \pm 1.71$ at 3 months $(P=0.678$ and 0.468 , respectively). The mean preoperative spherical equivalent was $+11.00 \pm 13.19$ diopters $(D)$, and the mean postoperative spherical equivalent was $+0.06 \pm 0.86 D(P<0.005)$. The mean IOL tilt was $2.4 \pm 1.7^{\circ}$, and the mean decentration was $0.35 \pm 0.21 \mathrm{~mm}$. The mean ACD was $4.31 \pm 0.29 \mathrm{~mm}$. Conclusions. The 27-gauge sutureless intrascleral PC-IOL implantation technique minimizes intraoperative injury, simplifies procedure, and provides good PC-IOL fixation with few postoperative complications.

\section{Introduction}

The absence of sufficient capsule support may happen as a result of incompetence of zonules [1], cataract surgery, vitreoretinal surgery, or following traumatic injury to anterior segment structures. In this situation, the fixation of an intraocular lens (IOL) is challenging and very variable. Various techniques of IOL fixation can be performed including anterior chamber IOL (AC-IOL) implantation, iris fixing posterior chamber IOL (PC-IOL) implantation, and transscleral sutured fixation of a PC-IOL in the ciliary sulcus or pars plana [2,3].

Transscleral suture fixation through the ciliary sulcus or the pars plana plays a principal role during the operation. But there are some severe postoperative complications in long-term studies [4-13], such as suture exposure, suture degradation, transient hypotony, and endophthalmitis. Gabor and Pavlidi
[14] first described a new technique of sutureless intrascleral fixation of a PC-IOL. Agarwal et al. [15] introduced a sutureless intrascleral technique with scleral flaps and fibrin glue. Yamane et al. [16] and Zhang et al. [17] developed the technique of sutureless intrascleral PC-IOL fixation to be more operable and convenient. Takayama et al. [18] advanced the sutureless intrascleral technique without applying a wide conjunctival incision. Barca et al. [19] introduced Carlevale lens to simplify the operation. However, postoperative complications still exist. In this case, we modified the technique and focused on the analysis of clinical outcomes and postoperative complications.

\section{Methods}

68 eyes of 66 patients who had received sutureless intrascleral haptics fixation of the PC-IOL under the $27 \mathrm{G}$ 
vitrectomy system between November 2017 and December 2019 were studied retrospectively. All surgeries were performed using the constellation vitrectomy 27+ vitrectomy system (Alcon Laboratories, Fort Worth, TX) by the same ophthalmologist at the Harbin Aier Eye Hospital, Harbin, China. The surgical protocol was approved by the Institutional Review Committee of Harbin Aier Eye Hospital, and all clinical investigations and procedures were conducted according to the principles of the Declaration of Helsinki of 1975, as revised in 2013. Informed consent was acquired from all the patients after being informed about the process and the possible complications of our technique.

Under peribulbar and subconjunctival anesthesia, a $4 \mathrm{~mm} \times 6 \mathrm{~mm}$ fornix-based peritomy was applied, and a standard 3-port 27G pars plana vitrectomy (PPV) was performed. During the operation, dislocated lens have been removed by lensectomy, phacoemulsification, or ultrasonic fragmentation according to the age of patients and hardness of lens nucleus. Then, a $3 \mathrm{~mm}$ sclerocorneal incision and two bilateral scleral dissections of $2 \mathrm{~mm}$ in length and about $0.5 \mathrm{~mm}$ thickness were performed $1.75 \mathrm{~mm}$ from the limbus (Figure 1). The two incisions were precisely $180^{\circ}$ apart from each other (Video 1). And two scleral punctures were conducted a 27G-stab knife at the bottom of the left incision and top of the right incision with slight extension.

Before, a standard 3-piece folded IOL (AcrySof MA60AC, Alcon or Tecnis ZA9003, AMO) was implanted with an injector through the sclerocorneal incision; a needle of a $1 \mathrm{ml}$ injector was bent at straight angle and was passed from a sclera puncture to sclerocorneal incision. The leading haptic was inserted into the needle and pulled out of the eye (Figure 2), and the trailing haptic was left outside the eye temporarily. The trailing haptic was sent into the anterior chamber by a $27 \mathrm{G}$ forceps through the sclerocorneal incision, and the end tip of the trailing haptic was then grasped and pulled out of the eye by another $27 \mathrm{G}$ forceps which was put through the right scleral puncture (Figure 3, Video 2). At the top of the left incision and the bottom of the right incision, two $3 \mathrm{~mm}$ scleral tunnels parallel to the limbus was prepared counterclockwise by a $29 \mathrm{G} \times 1 / 2^{\prime \prime}$ needle which has been bent at right angles in advance (Figure 4 ). Then, both the leading haptic and the trailing haptic were pulled into the scleral tunnel by $27 \mathrm{G}$ forceps, respectively (Video 3 ). The IOL was centered through adjusting the intrascleral position of both haptics (Figure 5). This surgery can be performed combining with perfluoropropan $\left(\mathrm{C}_{3} \mathrm{~F}_{8}\right)$ or silicone oil tamponade for retinal attachment. At last, the infusion cannula can be removed, and conjunctiva can be fixed with 8-0 absorbable sutures.

The best-corrected visual acuity (BCVA), intraocular pressure (IOP), IOL tilt, IOL decentration, anterior chamber depth (ACD), and complications were determined. Scheimpflug imaging (OCULUS PENTACAM) and ultrasound biomicroscopy (UBM) (SW-3200L SUOYA) were performed to evaluate the tilted angle and decentration distance of the IOL and anterior chamber depth (ACD) for each eye and corneal topography (K1 and $K 2) 3$ months postoperatively. The IOL tilt and decentration were measured and calculated in both the vertical and horizontal planes. The decimal BCVA was converted to the logarithm of the minimum angle of resolution (logMAR) for the statistical analyses. The Wilcoxon signed-rank test was used to determine the significance of any association between the preoperative and postoperative BCVA and IOP. $P<0.05$ was considered significant. The statistical analyses were performed using the SPSS software (version 22.0 for Windows SPSS, Inc.,Chicago, IL).

\section{Results}

Our surgical study consisted of 68 eyes of 66 patients (47 men and 19 women) with a mean age of 61 years (range 25-82 years), including 27 aphakia with incomplete lens capsule, 8 dislocated PC-IOLs, 22 subluxated crystalline lenses, and 11 luxated crystalline lenses (Tables 1 and 2). 33 lens have been removed with phacoemulsification, 15 lenses with ultrasonic fragmentation, and 13 lenses with lensectomy. The rest were extracted by other surgeons from other hospitals. The mean follow-up was 10 months. There was no postoperative retinal detachment, endophthalmitis, or IOL haptics exposure detected during the follow-up period.

The mean preoperative BCVA was $1.63 \pm 1.24 \log \mathrm{MAR}$ units, and the mean postoperative BCVA improved significantly to $0.74 \pm 0.59 \log$ MAR units at 3 months $(P<0.05)$. The mean preoperative IOP was $21.9 \pm 12.6 \mathrm{mmHg}$, and the mean postoperative IOP was $16.9 \pm 4.5 \mathrm{mmHg}$ at 3 months $(P=0.001)$ (Table 3$)$. The mean IOL tilt was $2.4 \pm 1.7^{\circ}$, and the mean decentration was $0.35 \pm 0.21 \mathrm{~mm}$. The mean ACD was $4.31 \pm 0.29 \mathrm{~mm}$. The mean preoperative corneal topography ( $K 1$ and $K 2$ ) was $K 1=42.14 \pm 1.91$ and $K 2=43.54 \pm 1.51$; the mean postoperative corneal topography $(K 1$ and $K 2)$ was $K 1=43.03 \pm 2.18$ and $K 2=43.40 \pm 1.71$ at 3 months $(P=0.678$ and 0.468 , respectively). The mean preoperative spherical equivalent was $+11.00 \pm 13.19$ diopters $(D)$, and the mean postoperative spherical equivalent was $+0.06 \pm 0.86 \mathrm{D}$ $(P<0.005)$. There were transient IOP rise $(4.5 \%)$, hyphema (3.0\%), vitreous hemorrhage $(1.5 \%)$, macular edema $(1.5 \%)$, haptic exposure $(3.0 \%)$, and pupillary capture $(8.8 \%)$ detected during the follow-up period.

\section{Discussion}

Secondary implantation and refixation of PC-IOL have been performed in patients with deficient capsular support after ocular surgery or trauma. As for AC-IOL implantation, though the postoperative corrected distance visual acuities (CDVA) was not significantly different from PC-IOL implantation [20], endothelial cell loss, pseudophakic bullous keratopathy, glaucoma, and chronic iritis [21-23] are still the main postoperative complications. And for iris-fixated IOL implantation, the main postoperative complications are chronic iritis, endothelial cell loss [24], and pupillary distortion [25]. For transscleral suture fixation, long-term studies revealed that suture exposure rate ranges from $5 \%$ to $50 \%$ [4-7]. Although, majority of surgeons placed the suture knots subconjunctivally or under a scleral flap [8] to avoid relatively high suture exposure. The ratio remains $14.7 \%-$ 


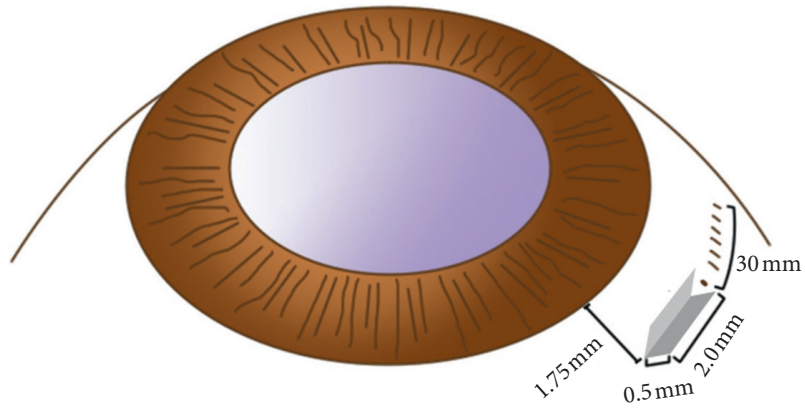

FIgURE 1: Diagram of position of scleral dissection.

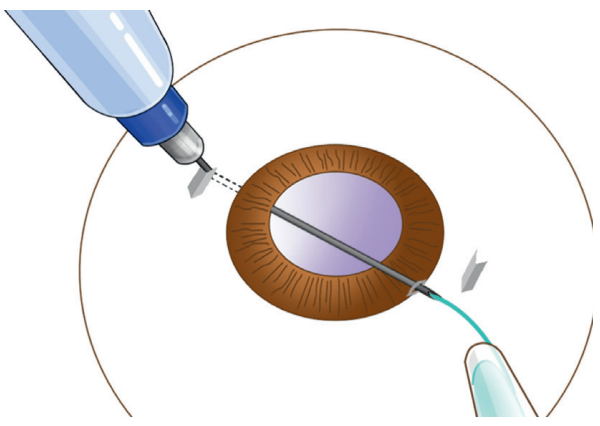

FIGURE 2: Diagram of the leading haptic guided by the needle.

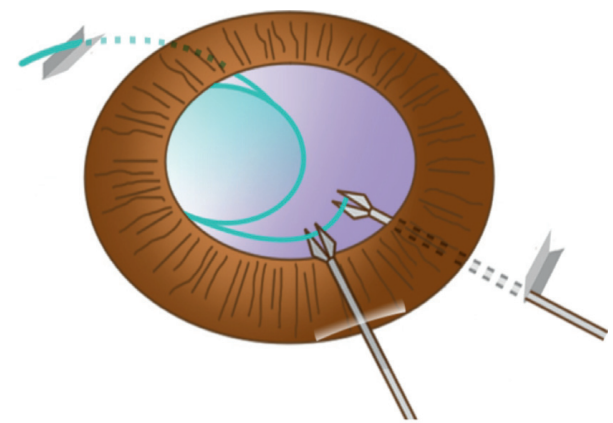

FIGURE 3: Diagram of the trailing haptic grasped by $27 \mathrm{G}$ forceps.

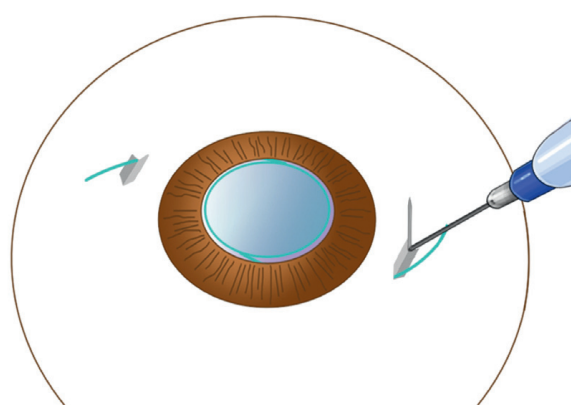

FIGURE 4: Diagram of the tunnel made by a bent $29 \mathrm{G} \times 1 / 2^{\prime \prime}$ needle.
17.9\% [9-11]. Girard [26] described a sutured technique for fixing the IOL through the pars plana; however, the decentration or tilt [27] of PC-IOL depends on suture hypotony or degradation [28], and endophthalmitis due to suture exposure [29] remains to be a problem. Surgeons applied for the Gore-Tex suture method which enables to improve problem of the suture degradation. However, the problem of transient hypotony and suture exposure still exists $[13,30]$.

Gabor and Pavlidis [14] reported sutureless intrascleral fixation of PC-IOL, in order to avoid the sutured PC-IOL situation and enable the PC-IOL more proximity to the ocular rotational axis and nodal point [31]. In Scharioth's technique, two scleral tunnels about $50 \%$ scleral thickness, starting directly from sclerotomies were performed by a 24gauge cannula, and the haptics were grasped and pulled out through the sclerotomies by a 25-gauge forceps. In our study, we updated the sclerotomies and entrances of scleral tunnels for haptics apart, which enabled the operator to pull the haptics into the tunnels much more easily.

Yamane et al. [16] externalized the haptics of the IOL and inserted the IOL haptics into the scleral tunnel in a more operable and convenient manner, as sclerotomy and scleral tunnel are apart. And two scleral tunnels were conducted by a $27 \mathrm{G}$ needle. During our study, the scleral tunnels were prepared by a $29 \mathrm{G} \times 1 / 2^{\prime \prime}$ needle and tightly sealed around the haptics, which stabilized the haptics. The cross-section diameter of a $27 \mathrm{G}$ needle is $0.4 \mathrm{~mm}$, while a $29 \mathrm{G} \times 1$ / $2^{\prime \prime}$ needle is $0.33 \mathrm{~mm}$ and an IOL haptic (Alcon AcrySof MA60AC) is $0.14 \mathrm{~mm}$. The $29 \mathrm{G} \times 1 / 2^{\prime \prime}$ needle was bent at right angles, and the distance between the tip and the bend point was $3 \mathrm{~mm}$. In our technique, the tunnels are tighter and the stability of IOL is better.

Agarwal et al. [15] introduced that sutureless PC-IOL implantation with glue, in which scleral flaps were performed and developed by Kumar et al. [32-34]. However, a possibility of transmission of viral infections theoretically existed [35], and a large lamellar scleral flap was required. Comparing to Amar and Kumar's technique, ours does less trauma and costs less.

Barca et al. [19] applied a novel one-piece foldable IOL named Carlevale lens which simplified the procedure and shortened the learning curve. And the fixation of Carlevale lens was stable due to the specially designed sclera-corneal plugs. These are all superior to 3-piece IOL sutureless intrascleral fixation technique. Rossi et al. [36] reported a $1.3 \%$ incidence of T-shaped Carlevale lens harpoon ruptured when grasped to externalize it in their study of 78 patients. The T-shaped Carlevale lens harpoon was much more diminutive than a 3-piece IOL haptic. In our technique, we applied a needle to guide the leading haptic, and the trailing haptic of 3-piece IOL was easier for surgeons to externalize.

Another $6(8.8 \%)$ patients suffered pupillary capture with iris depigmentation (Figures 6 and 7), at 2 weeks after operation. The IOP of three was $16 \sim 18 \mathrm{mmHg}$ and pupil was dilatate. Then, Nd:YAG laser iridotomy was performed on one patient to improve the situation. In 3 studies reported by Kumar et al. [33, 34, 37], the incidence of pupillary capture is $4.30 \%, 2.63 \%$, and $2.40 \%$, respectively, while Shin et al. [16] 


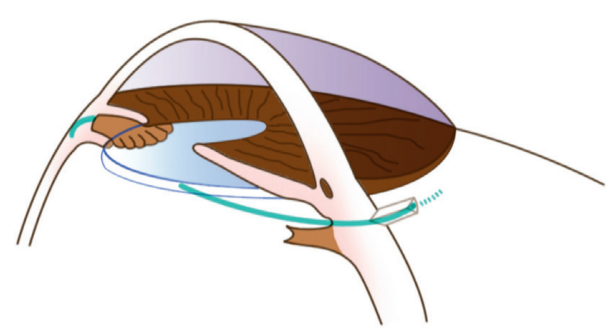

Figure 5: Diagram of position of haptics.

TABLE 1: Indications for surgery.

\begin{tabular}{lcccc}
\hline & Trauma & Incompetence of zonules & Cataract surgery & Vitreoretinal surgery \\
\hline Aphakia with incomplete lens capsule & 13 & 2 & 6 & 6 \\
Subluxated crystalline lenses & 12 & 7 & 7 & 0 \\
Luxated crystalline lenses & 4 & 5 & 0 & 0 \\
Dislocated PC-IOLs & 3 & 7 & 0 \\
\hline
\end{tabular}

TABLE 2: Characteristics.

\begin{tabular}{lccccc}
\hline & $\begin{array}{c}\text { Ocular } \\
\text { hypertension }\end{array}$ & $\begin{array}{c}\text { Vitreous } \\
\text { prolapse }\end{array}$ & High myopia & $\begin{array}{c}\text { Traumatic } \\
\text { hyphema }\end{array}$ & Silicone oil filled eye \\
\hline Aphakia with incomplete lens capsule & 5 & 0 & 0 & 0 & 9 \\
Subluxated crystalline lenses & 6 & 4 & 1 & 2 & 0 \\
Luxated crystalline lenses & 3 & 2 & 2 & 0 & 0 \\
Dislocated PC-IOLs & 0 & 0 & 3 & 0 & 0 \\
\hline
\end{tabular}

TABLE 3: Comparison of BCVA and IOP before and after management.

\begin{tabular}{lcc}
\hline & Preoperative & Postoperative (3 months) \\
\hline BCVA (logMAR units) & $1.63 \pm 1.24$ & $0.74 \pm 0.59$ \\
IOP (mmHg) & $21.9 \pm 12.6$ & $16.9 \pm 4.5$ \\
\hline
\end{tabular}

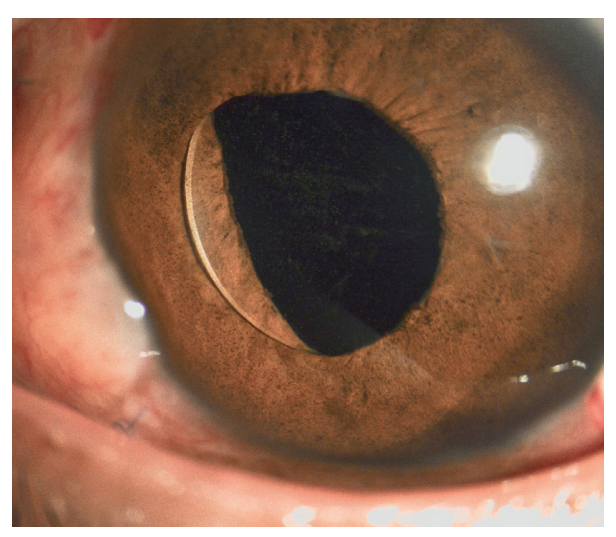

FIGURE 6: Photography of pupillary capture.

and Takayama et al. [18] reported it to be $8.60 \%$ and $8.30 \%$. Shin et al. [16] performed a peripheral iridotomy by a vitrectomy cutter to avoid iris capture of the IOL, but pupillary capture remains the highest rate of postoperative complication in their study. There was no pupillary capture occurred in studies of Carlevale lens $[19,36,38,39]$. There is a $5^{\circ}$ anterior angulation relative to the optic plate of Carlevale lens haptics to ensure enough space between iris and IOL, which may minimize iris chafing and pupillary capture. During the surgery, the two conditions might happen: pupillary dilatation on account of the injured sphincter pupillae muscle $[40,41]$ and IOL decentration owing to 


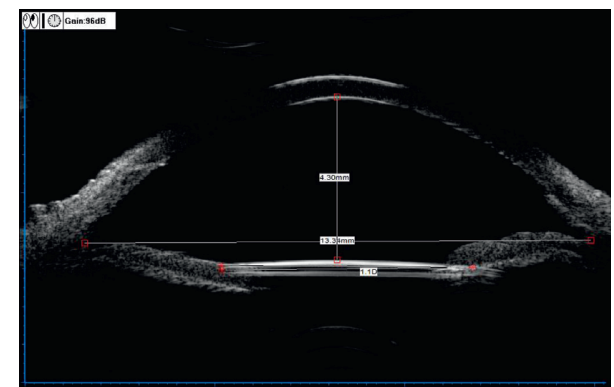

FIgURE 7: Anterior chamber depth measured by UBM.

asymmetric fixation [42]. After the surgery, the removal of the lens capsule and the lens zonular fibers with vitreous preserved a greater posterior chamber volume resulted in iris backward and more aqueous humor flowing into the anterior chamber $[43,44]$ to push IOL up. And iris depigmentation due to the contact between IOL and the iris pigment epithelium might cause angle pigmentation, which slowed the aqueous humor flowing out from the anterior chamber [45]. We speculated these four reasons are responsible for pupillary capture. In our study, the mean ACD was $4.31 \pm 0.29 \mathrm{~mm}$, which comparing to $4.47 \pm 0.31 \mathrm{~mm}$ in capsular bag reported by Hoffer and Savini [46] was a little shallower. Choi et al. [42] reported the ACD was significantly shallower in the eyes with IOL capture, while Kang and Kim [47] reported that a larger ACD increased the risk for pupillary capture. Therefore, further study of large sample is essential to explain whether there is the potential relationship between pupillary capture and ACD.

In the study, four eyes were diagnosed as intraocular hypertension preoperatively, including three eyes that suffered vitreous prolapse and one eye that suffered traumatic hyphema. Vitreous and blood might occlude the angle of the anterior chamber and increase intraocular pressure for the patients. The $27 \mathrm{G}$ vitrectomy system represented that its cutter is sufficient to cutoff vitreous and blood in the angle.

Two patients $(2.9 \%)$ suffered hyphema and one patient (1.5\%) suffered vitreous hemorrhage on the first day after surgery. There were some small patches of blood on the iris and a little bit of blood in the vitreous chamber. After 2 or 3 days, blood was absorbed, and neither hyphema nor vitreous hemorrhage appeared during the next follow-up period.

The haptics of two high myopia patients $(2.9 \%)$ came out postoperatively, as the sclera of theirs was thinner than normal people. We had to suture the scleral dissections and tunnels. So, we suggest that when dealing with patients with high myopia, surgeons should be careful of the thin sclera. And it is reported that maybe it is not appropriate for the eyes with thin sclera, scleritis, areas of scleromalacia, and staphyloma [48, 49].

One special case presented that dissections and tunnels were performed superior and inferior and precisely $180^{\circ}$ apart from each other. This was different from horizontal dissections of other cases and IOL stability remains.

A 25-year-old female Marfan's syndrome patient who suffered from dislocated crystalline lens received the fixation. It is more beneficial to young patients to apply for our technique, as less trauma and self-sealing sclerotomy injury.
Taken together, the 27-gauge sutureless intrascleral PCIOL implantation technique with $29 \mathrm{Gi} 1 / 2^{\prime \prime}$ needle minimizes intraoperative trauma, simplifies procedure, and provides good PC-IOL fixation with few postoperative complications currently. Although sutureless intrascleral PC-IOL fixation were reported previously, the long-term anatomical and functional stay would be considered.

\section{Abbreviations \\ BCVA: Best-corrected visual acuity \\ IOL: Intraocular lens. \\ PC-IOL: Posterior chamber intraocular lens \\ AC-IOL: Anterior chamber intraocular lens \\ IOP: Intraocular pressure \\ ACD: Anterior chamber depth \\ D: $\quad$ Diopters \\ PPV: Pars plana vitrectomy \\ UBM: Ultrasound biomicroscopy \\ CDVA: Corrected distance visual acuities.}

\section{Data Availability}

The datasets analyzed during the current study are available from the corresponding author upon request.

\section{Conflicts of Interest}

The authors declare that they have no conflicts of interest.

\section{Acknowledgments}

This work was supported by grant from Clinical Medical Technology Innovation Guidance Project in Hunan Province, China (2018SK50101).

\section{Supplementary Materials}

Video 1. Determining the position of IOL (). Video 2. IOL implantation (). Video 3. Haptics of IOL fixation (). (Supplementary Materials)

\section{References}

[1] P. Dureau, "Pathophysiology of zonular diseases," Current Opinion in Ophthalmology, vol. 19, no. 1, pp. 27-30, 2008.

[2] K. P. Dajee, A. M. Abbey, and G. A. Williams, "Management of dislocated intraocular lenses in eyes with insufficient capsular support," Current Opinion in Ophthalmology, vol. 27, no. 3, pp. 191-195, 2016.

[3] R. S. Hoffman, M. E. Snyder, U. Devgan et al., "Management of the subluxated crystalline lens," Journal of Cataract \& Refractive Surgery, vol. 39, no. 12, pp. 1904-1915, 2013.

[4] D. G. Heidemann and S. P. Dunn, "Transsclerally sutured intraocular lenses in penetrating keratoplasty," American Journal of Ophthalmology, vol. 113, no. 6, pp. 619-625, 1992.

[5] A. J. Lubniewski, E. J. Holland, W. S. Van Meter, D. Gussler, J. Parelman, and M. E. Smith, "Histologic study of eyes with transsclerally sutured posterior chamber intraocular lenses," American Journal of Ophthalmology, vol. 110, no. 3, pp. 237-243, 1990. 
[6] E. Epstein, "Suture problems," Journal of Cataract \& Refractive Surgery, vol. 15, no. 1, p. 116, 1989.

[7] N. Majunke, A. Baranowski, W. Zimmermann et al., "A suture not always the ideal solution: problems encountered in developing a suture-based PFO closure technique," Catheterization and Cardiovascular Interventions, vol. 73, 2008.

[8] S. B. Hannush, "Sutured posterior chamber intraocular lenses: indications and procedure," Current Opinion in Ophthalmology, vol. 11, no. 4, pp. 233-240, 2000.

[9] D. Uthoff and K. D. Teichmann, "Secondary implantation of scleral-fixated intraocular lenses," Journal of Cataract \& Refractive Surgery, vol. 24, no. 7, pp. 945-950, 1998.

[10] Z. Yalniz-Akkaya, I. Abay, M. Acar et al., "Primary and secondary implantation of scleral-fixated posterior chamber intraocular lenses in adult patients," Middle East African Journal of Ophthalmology, vol. 21, no. 1, pp. 44-49, 2014.

[11] K. Solomon, J. R. Gussler, C. Gussler, and W. S. Van Meter, "Incidence and management of complications of transsclerally sutured posterior chamber lenses," Journal of Cataract \& Refractive Surgery, vol. 19, no. 4, pp. 488-493, 1993.

[12] M. A. Khan, O. P. Gupta, R. G. Smith et al., "Scleral fixation of intraocular lenses using Gore-Tex suture: clinical outcomes and safety profile," British Journal of Ophthalmology, vol. 100, no. 5, pp. 638-643, 2016.

[13] M. A. Khan, E. Rahimy, O. P. Gupta, and J. Hsu, "Combined 27-gauge pars plana vitrectomy and scleral fixation of an akreos AO60 intraocular lens using gore-tex suture," Retina, vol. 36, no. 8, pp. 1602-1604, 2016.

[14] S. G. B. Gabor and M. M. Pavlidis, "Sutureless intrascleral posterior chamber intraocular lens fixation," Journal of Cataract \& Refractive Surgery, vol. 33, no. 11, pp. 1851-1854, 2007.

[15] A. Agarwal, D. A. Kumar, S. Jacob, C. Baid, A. Agarwal, and S. Srinivasan, "Fibrin glue-assisted sutureless posterior chamber intraocular lens implantation in eyes with deficient posterior capsules," Journal of Cataract \& Refractive Surgery, vol. 34, no. 9, pp. 1433-1438, 2008.

[16] S. Yamane, M. Inoue, A. Arakawa, and K. Kadonosono, "Sutureless 27-gauge needle-guided intrascleral intraocular lens implantation with lamellar scleral dissection," Ophthalmology, vol. 121, no. 1, pp. 61-66, 2014.

[17] Y. Zhang, F. He, J. Jiang, Q. Li, and Z. Wang, "Modified technique for intrascleral fixation of posterior chamber intraocular lens without scleral flaps," Journal of Cataract \& Refractive Surgery, vol. 43, no. 2, pp. 162-166, 2017.

[18] K. Takayama, M. Akimoto, H. Taguchi, S. Nakagawa, and K. Hiroi, "Transconjunctival sutureless intrascleral intraocular lens fixation using intrascleral tunnels guided with catheter and 30-gauge needles," British Journal of Ophthalmology, vol. 99, no. 11, pp. 1457-1459, 2015.

[19] F. Barca, T. Caporossi, L. de Angelis et al., "Trans-scleral plugs fixated IOL," Journal of Cataract \& Refractive Surgery, vol. 46, no. 5, pp. 716-720, 2020.

[20] Y. Zhang, D. Sun, Z. Zhang, H. Xiao, and S. Peng, "Combined silicone oil removal with secondary implantation of anterior chamber or sclera-fixed posterior chamber intraocular lenses," European Journal of Ophthalmology, vol. 23, no. 5, pp. 697-704, 2013.

[21] A. Numa, J. Nakamura, M. Takashima, and K. Kani, "Longterm corneal endothelial changes after intraocular lens implantation. Anterior vs posterior chamber lenses," Japanese Journal of Ophthalmology, vol. 37, no. 1, pp. 78-87, 1993.

[22] P. W. Smith, S. K. Wong, W. J. Stark, J. D. Gottsch, A. C. Terry, and R. D. Bonham, "Complications of semiflexible, closed-loop anterior chamber intraocular lenses," Archives of Ophthalmology (Chicago, Ill: 1960), vol. 105, pp. 52-57, 1987.

[23] D. J. Apple, R. N. Brems, R. B. Park et al., "Anterior chamber lenses. Part I: complications and pathology and a review of designs," Journal of Cataract \& Refractive Surgery, vol. 13, no. 2, pp. 157-174, 1987.

[24] J. L. Menezo, A. L. Cisneros, and V. Rodriguez-Salvador, "Endothelial study of iris-claw phakic lens: four year followup," Journal of Cataract \& Refractive Surgery, vol. 24, no. 8, pp. 1039-1049, 1998.

[25] B. Clément, R. Montard, G. Creisson, O. Lebreton, and M. Montard, "Étude de la motilité pupillaire chez le sujet phaque porteur d'un implant Artisan," Journal Français d'Ophtalmologie, vol. 29, no. 4, pp. 404-408, 2006.

[26] L. J. Girard, "Pars plana phacoprosthesis (aphakic intraocular implant): a preliminary report," Ophthalmic Surgery, Lasers and Imaging Retina, vol. 12, pp. 19-22, 1981.

[27] R. R. Berger and A. M. Kenyeres, "The torque and tilt gamble," Journal of Cataract \& Refractive Surgery, vol. 23, no. 10, pp. 1433-1434, 1997.

[28] A. S. McAllister and L. W. Hirst, "Visual outcomes and complications of scleral-fixated posterior chamber intraocular lenses," Journal of Cataract \& Refractive Surgery, vol. 37, no. 7, pp. 1263-1269, 2011.

[29] T. Heilskov, B. C. Joondeph, K. R. Olsen, and G. W. Blankenship, "Late endophthalmitis after transscleral fixation of a posterior chamber intraocular lens," Archives of Ophthalmology (Chicago, Ill: 1960), vol. 107, p. 1427, 1989.

[30] M. A. Khan, O. P. Gupta, R. G. Smith et al., "Scleral fixation of intraocular lenses using Gore-Tex suture: clinical outcomes and safety profile," British Journal of Ophthalmology, vol. 100, no. 5 , p. $638,2016$.

[31] M. S. Arkin and R. F. Steinert, "Sutured posterior chamber intraocular lenses," International Ophthalmology Clinics, vol. 34, no. 3, pp. 67-85, 1994.

[32] D. A. Kumar, A. Agarwal, S. Jacob, G. Prakash, and A. Agarwal, "Use of 23-gauge or 25-gauge trocar cannula for globe maintenance in glued intraocular lens surgery," Journal of Cataract \& Refractive Surgery, vol. 36, no. 4, pp. 690-691, 2010.

[33] D. A. Kumar, A. Agarwal, A. Agarwal, G. Prakash, and S. Jacob, "Glued intraocular lens implantation for eyes with defective capsules: a retrospective analysis of anatomical and functional outcome," Saudi Journal of Ophthalmology, vol. 25, no. 3, pp. 245-254, 2011.

[34] D. A. Kumar and A. Agarwal, "Glued intraocular lens: a perspective," Expert Review of Ophthalmology, vol. 8, pp. 355-361, 2014.

[35] A. Schlegel, A. Immelmann, and C. Kempf, "Virus inactivation of plasma-derived proteins by pasteurization in the presence of guanidine hydrochloride," Transfusion, vol. 41, no. 3, pp. 382-389, 2001.

[36] T. Rossi, D. Iannetta, V. Romano et al., "A novel intraocular lens designed for sutureless scleral fixation: surgical series," Graefe's Archive for Clinical and Experimental Ophthalmology, vol. 259, no. 1, pp. 257-262, 2020.

[37] D. A. Kumar and A. Agarwal, "Glued intraocular lens," Current Opinion in Ophthalmology, vol. 24, no. 1, pp. 21-29, 2013.

[38] A. Mularoni, A. Imburgia, M. Forlini, L. Rania, and G. L. Possati, "In vivo evaluation of a one-piece foldable sutureless intrascleral fixation lens using ultrasound biomicroscopy and anterior segment optical coherence tomography," Journal of Cataract and Refractive Surgery, 2020. 
[39] C. Veronese, C. Maiolo, G. W. Armstrong et al., "New surgical approach for sutureless scleral fixation," European Journal of Ophthalmology, vol. 30, no. 3, pp. 612-615, 2020.

[40] M. Lavin and J. Jagger, "Pathogenesis of pupillary capture after posterior chamber intraocular lens implantation," British Journal of Ophthalmology, vol. 70, no. 12, pp. 886-889, 1986.

[41] V. Y. W. Lee, J. L. Tang, D. T. L. Liu, V. C. K. Chan, C. L. Li, and D. S. C. Lam, "Prospective randomized comparative study of the effect of pupil dilation or miosis in intraocular lens pupillary capture after combined phacoemulsification and vitrectomy with intraocular tamponade," Asia-Pacific Journal of Ophthalmology, vol. 1, no. 2, pp. 72-76, 2012.

[42] S. R. Choi, J. H. Jeon, J. W. Kang, and J. W. Heo, "Risk factors for and management of pupillary intraocular lens capture after intraocular lens transscleral fixation," Journal of Cataract \& Refractive Surgery, vol. 43, no. 12, pp. 1557-1562, 2017.

[43] H. Itagaki, T. Kunikata, K. Hiratsuka, J. Saito, and T. Oshika, "Reverse pupillary block associated with pigment dispersion syndrome after in-the-bag intraocular lens implantation," Journal of Cataract \& Refractive Surgery, vol. 39, no. 12, pp. 1925-1928, 2013.

[44] H. Singh, M. Modabber, S. G. Safran, and Ahmed, "Laser iridotomy to treat uveitis-glaucoma-hyphema syndrome secondary to reverse pupillary block in sulcus-placed intraocular lenses: case series," Journal of Cataract \& Refractive Surgery, vol. 41, no. 10, pp. 2215-2223, 2015.

[45] S. P. Bang, C.-K. Joo, and J. H. Jun, "Reverse pupillary block after implantation of a scleral-sutured posterior chamber intraocular lens: a retrospective, open study," BMC Ophthalmology, vol. 17, no. 1, p. 35, 2017.

[46] K. J. Hoffer and G. Savini, "Anterior chamber depth studies," Journal of Cataract \& Refractive Surgery, vol. 41, no. 9, pp. 1898-1904, 2015.

[47] D. J. Kang and H. K. Kim, "Clinical analysis of the factors contributing to pupillary optic capture after transscleral fixation of posterior chamber intraocular lens for dislocated intraocular lens," Journal of Cataract \& Refractive Surgery, vol. 42, no. 8, pp. 1146-1150, 2016.

[48] B. Todorich, A. Thanos, M. A. Woodward, and J. D. Wolfe, "Sutureless intrascleral fixation of secondary intraocular lens using 27-gauge vitrectomy system," Ophthalmic Surgery, Lasers and Imaging Retina, vol. 47, no. 4, pp. 376-379, 2016.

[49] Y. Matsui, H. Matsubara, T. Hanemoto, and M. Kondo, "Exposure of haptic of posterior chamber intraocular lens after sutureless intrascleral fixation," BMC Ophthalmology, vol. 15, no. 1, p. 104, 2015. 